\title{
Lung transplantation: the patient view from either side of the operating table
}

Lung transplantation is the fourth most common type of solid organ transplant, with over 5000 taking place worldwide in 2015 [1]. This article describes the experiences of two patients, one waiting for a lung transplant, the other a lung transplant recipient.

Even though he is not ready to go on the list, Ron Flewett (figure 1) and his wife Maxine have already begun to prepare for the possibility of a lung transplant. They have made sure their mobile phones are on different networks in case one of them is out of range when the vital call comes through. They have bought the motorhome that Maxine will stay in to be close to the hospital where Ron's transplant will take place, and where Ron can stay for a month after discharge when he will have regular appointments for tests. Ron has even changed his diet and lost weight to be as physically prepared as possible. But being mentally prepared is a bit more of a stretch: although he feels lucky to have the chance of a transplant, Ron admits to being "petrified" at the thought of going through the surgery.

Beatriz Salgueiro (figure 2) from Portugal knows what Ron is going through as she has been through the procedure not once, but twice. Beatriz was in her early twenties when lung damage caused by a childhood infection led to her needing to use portable oxygen and a suggestion from her consultant that she consider a transplant. Beatriz was not surprised by the idea as she had already done her research and knew that her condition would worsen and only a transplant would give her the opportunity of "something resembling a normal life". What did surprise her was that she was only on the waiting list for a few months before getting a call. However, that first call, and another that followed, turned out to be false alarms: in 2019 in the Eurotransplant zone (Austria, Belgium, Croatia, Germany, Hungary, Luxembourg, the Netherlands and Slovenia), only $20 \%$ of lungs donated were eventually transplanted (www.eurotransplant. org). The fragile nature of lungs means that there are usually restrictive criteria for acceptance for transplant, including no history of heavy smoking or cancer [2], although clinicians are increasingly willing to transplant lungs outside of these parameters [3].

Ron, from the UK, was diagnosed with idiopathic pulmonary fibrosis (IPF) at the age of 53 and was told his life expectancy was between 3 and 5 years. 6 years on and he is doing all he can to stay off the transplant list, especially with the threat of COVID-19. Not only have clinicians been reluctant to carry out transplants during the pandemic, but they are also advised against accepting lungs from a donor who has had COVID-19, potentially reducing the number of organs available for transplantation [4]. Twice a week Ron completes a home spirometry test to measure his forced vital capacity (FVC). A man of Ron's age and build should have an FVC of $3.97 \mathrm{~L}$. Ron's is $2.1 \mathrm{~L}$, and he knows that if it drops by even $0.1 \mathrm{~L}$, this indicates a decline in lung function and he will be added to the transplant list.

@ERSpublications

The experiences of two patients: one waiting for a lung transplant, the other a lung transplant recipient https://bit.ly/3alvxbm

Cite as: Williams $C$ Flewett R, Salgueiro B. Lung transplantation: the patient view from either side of the operating table. Breathe 2021; 17: 200305.
(1)

CrossMark 


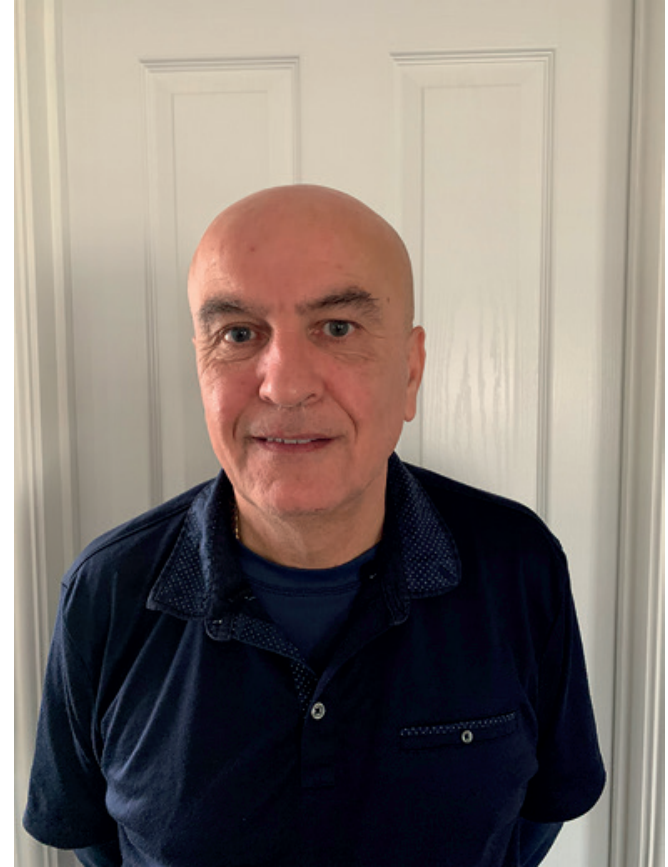

Figure 1 Ron Flewett.

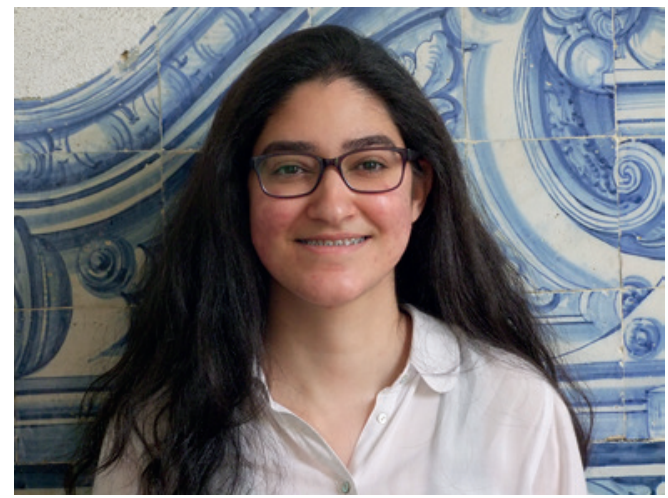

Figure 2 Beatriz Salgueiro.

Ron says that one of his biggest fears is that he will miss the "window of opportunity" to go on the waiting list. If his health declines too much, he might no longer be suitable: he needs to be sick enough to need a transplant, but not too sick to prevent the transplant going ahead. At the start of 2019 there were 715 people on the waiting list for a lung transplant in the Eurotransplant area; by the end of the year 67 patients had died before being offered suitable lungs and 29 had been removed from the list as no longer suitable for transplant (www.eurotransplant.org).

As part of the preparation to be considered for a transplant, Ron underwent several days of assessments, which he describes as an "interrogation" - but necessary to make sure he was a suitable candidate. It covered his lifestyle, mental health, relationships and support networks as well as the medical and physical side, and the risks associated with transplant - in Ron's words - he might be "swapping one set of problems for another". A transplant might extend his life and free him from needing to use oxygen and take IPF medications that have caused side-effects such as extreme fatigue and severe diarrhoea. However, he will need to take immunosuppressant medication for the rest of his life, and this means he will be at increased risk of infection, kidney disease, diabetes and certain cancers. Ron believes it is important that healthcare professionals are honest with patients and families about the risks, so they can base their decisions on the facts. And it was important for Ron's wife to be included in the consultations, as she will be by her husband's side throughout the procedure and the recovery afterwards.

A major risk is that Ron's body will reject the new organ, and it was this that led to Beatriz needing a second transplant. Following her first transplant, Beatriz, then aged 23, spent 21 days in hospital. She then had 4 months of physiotherapy after which she felt "better than ever", but a few years later she began to feel tired and breathless. She was diagnosed with chronic lung allograft dysfunction (CLAD), more commonly known as rejection. CLAD is not uncommon: in one study, $43.4 \%$ of lung transplant recipients experienced it [5]. For 6 months, Beatriz's doctors tried everything. She was given steroids followed by an anti-thymocyte globulin anti-rejection agent, but the CLAD continued to get worse so Beatriz was put back on the transplant list. She moved from portable oxygen, to noninvasive ventilation, to a highflow nasal cannula before finally being put onto extracorporeal membrane oxygenation (ECMO). Reserved for the most seriously ill patients, ECMO supports failing lungs by pumping a person's blood through a machine that removes carbon dioxide and infuses it with oxygen before it is returned to the body. Only $55 \%$ of adults who undergo ECMO survive [6]. Beatriz was one of them: after a week on the machine, she was offered a new set of lungs.

Beatriz's recovery from her second transplant was slower than the first, which she puts down to her being in poorer physical condition. While before the first transplant she could continue with her studies, before the second she could not move without becoming breathless and had spent a month in hospital. Following the second transplant Beatriz says that her whole body felt different: she needed help to get up, her balance felt off and everything felt difficult, in contrast to her first transplant where she felt well almost immediately.

A year on from her second transplant and now aged 27, Beatriz's health has improved. She takes seven different medications, including immunosuppressants, anti-rejection agents, beta blockers, steroids, antibiotics and antifungals, plus a proton pump inhibitor, as acid reflux is associated with poor outcomes for lung transplant patients. The main side-effects she experiences are tremors and unwanted hair growth. She feels lucky because she knows others who take many more medications with a greater side-effect burden. She can move, 
run, carry heavy things, and she no longer gets tired just from getting out of a chair. For Beatriz, whose life previously felt constrained, these small things are really important. The COVID-19 pandemic has prevented her from going out and experiencing life and taking advantage of new opportunities. But she knows she must be careful. She does not want to waste everything she has been through and the work and dedication of everyone involved in the process that has allowed her to be here as she is today.

What advice would Beatriz offer to patients like Ron, as they await their transplant? She would suggest staying active for as long as possible, to make recuperation easier, but also eating the foods they love because there will be dietary restrictions after transplant which can be particularly difficult. It was important for Beatriz to get as much information as possible from the medical team, as being informed and aware of every part of the process helped her to prepare and accept what was about to happen. She would also advise not being embarrassed to seek support from family, friends and healthcare professionals. Most of the time they will want to help but might not know how. And most importantly of all, Beatriz says, never ever give up. Your time will come.

And what about after the transplant? Beatriz says: live your life the best you can for as long as you can. Provided you follow the advice of your doctors, do not let anyone else stop you. Live your present, invest in your future. Stop thinking of yourself as a patient or someone who is sick. You are a person with dreams and aspirations and now your body can keep up with your head. Do not let that go to waste.

Affiliations

Clare Williams $^{1}$, Ron Flewett ${ }^{1,2}$, Beatriz Salgueiro ${ }^{1,3}$

${ }^{1}$ European Lung Foundation, Sheffield, UK. ${ }^{2}$ Pulmonary Fibrosis Trust, Lichfield, UK. ${ }^{3}$ Associação de Transplantados Pulmonares de Portugal, Lisbon, Portugal.

\section{Conflict of interest}

C. Williams is an employee of the European Lung Foundation.

\section{References}

1. Mahillo B, Carmona M, Alvarez M, et al. Worldwide distribution of solid organ transplantation and access of population to those practices. Transplantation 2018; 102: S71-S72.

2. Orens JB, Boehler A, de Perrot $M$, et al. A review of lung transplant donor acceptability criteria. J Heart Lung Transplant 2003; 22: 1183-1200.

3. Abelson J, Glanville AR. Controversies and emerging topics in lung transplantation. Breathe 2018; 14: 278-287.

4. Shigemura N, Cordova F, Criner G, et al. Current precautions and future directions in lung transplantation during the COVID-19 pandemic - a single center cohort study. Transp/ Int 2020; 33 : 1453-1457.

5. Combs MP, Wheeler DS, Belloli EA, et al. Prevalence and prognosis of updated phenotypes of chronic lung allograft dysfunction. J Heart Lung Transplant 2020; 39: S162-S163.

6. Paden ML, Conrad SA, Rycus PT, et al. Extracorporeal Life Support Organization Registry international report 2016. ASAIO J 2017; 63: 60-67. 